\title{
Do we understand sustainability? An architectural insight into the origin of the concept
}

\author{
Author: TUSHAR MONDAL \\ Teaching Faculty, Periyar School of Architecture \\ tushar.mondal.19@alumni.ucl.ac.uk \\ https://orcid.org/0000-0001-8108-176X
}

\begin{abstract}
Sustainability is a concept shrouded in abstraction. While we have definitions in existence, it is often difficult to explain the concept itself. The current definition of 'sustainable development' was given by the Brundtland Commission's report in 1987. The Earth Summit at Rio in 1992 gave us Agenda 21, an action plan to achieve sustainable development. Now in the $21^{\text {st }}$ century, philosophers, academicians, and researchers across the globe are paving the way for a new understanding of the term 'sustainability', its contextual nature, and its relation to humans, politics, and ecology. This article investigates the origins of the term 'sustainability', its derivatives, and the concept of sustainable development. A semantical analysis is carried out to understand the differences between 'sustainability' and 'sustainable development'. Next, the development of the three pillars of sustainability and the application of these concepts in the field of architecture and design is also investigated.
\end{abstract}

Keywords: architecture, sustainability, sustainable development, sustainable design

\section{Introduction}

The term 'sustainability' is often used as the umbrella term for that near-perfect state of any working model, the optimised version, which all development should ideally be focussed on achieving. It is an abstraction of the end-goal which an agent would need to somehow achieve to successfully survive. On the other hand, 'sustainable development' is the term used for any number of steps and goals which need to be fulfilled to attain 'sustainability'. They are tangible, laid out plans which can be achieved in a fixed amount of time with a structured pathway leading towards them. UNESCO clarifies the difference between the two as follows "Sustainability is often thought of as a long-term goal (i.e., a more sustainable world), while sustainable development refers to the many processes and pathways to achieve it (e.g., sustainable agriculture and forestry, sustainable production and consumption, good 
government, research and technology transfer, education and training, etc.)" (United Nation's Education, Scientific and Cultural Organisation, n.d.).

As previously mentioned, the Brundtland Commission's report of 1987, also known as 'Report of the World Commission on Environment and Development: Our Common Future', gives us the definition of 'sustainable development' (World Commission on Environment and Development, 1987). Despite that, the document does not state a clear definition of the term 'sustainability'. The document also uses the two terms interchangeably. There are two observations to be made from this. First, that the concept of 'sustainability' is extremely abstract and convoluted, making it difficult to attach any concrete definition to it; it currently refers to a set of ideals and principles, which are used as benchmarks to determine how sustainable the model is. Second, most of the suggestions by the document, and documents subsequently published on the general topic, define, and talk majorly about 'sustainable development', and how to achieve it; most research in the late twentieth and early twenty-first centuries focussed on sustainable development, where the two terms were liberally substituted for each other. B As Paul Warde explains in his book The Invention of Sustainability, 'Formulations of sustainability are frequently rather vague, but they generally address the sense that humankind must ensure its material reproduction in a way that does not diminish the fortunes of future generations' (Warde, 2011).

\section{$1 \quad$ Research Methodology}

The investigation was carried out through a chronological review of the existing literature on sustainability. A primary etymological study was conducted to determine the origin of the terms 'sustain', 'sustainability' and 'sustainable development'. This was also supported by a literary analysis of the same terms in two other languages - Hindi and Bengali. The two languages were chosen due to the author's proficiency in them, being a native speaker. To track the origin and evolution of the concepts, a literature study covering a plethora of secondary sources was conducted. A particular emphasis was laid on the multiple international summits on climate change summits organised from the late 1960s to the present, for which reports are available in the public domain. To track the evolution of the concept, a summative analysis was carried out of these reports, which included Our Common Future, Rio Summit 1992 and Agenda 21, Earth + 5 Summit 1997, World Summit on Sustainable Development 2002, and Rio+20 summit in 2012. Further, publications, books, and research papers by prominent thinkers of the $21^{\text {st }}$ century who have spoken about sustainability were inspected. 


\section{Semantical Analysis}

Both the terms 'sustainability' and 'sustainable' (development) originate from the term 'sustain'. The Oxford English Dictionary defines sustain as 'to support, maintain or uphold', its origin being a borrowing from the French word susteiner (Oxford English Dictionary, n.d.). As derivatives of this word, both 'sustainability' and 'sustainable' (development) have similarly related original meanings. While the origin of the term 'sustainable' can be traced back to the 1600 s, the definition predominantly associated with it is "capable of being maintained or continued at a certain rate or level'. This definition can be traced back to 1924 (Oxford English Dictionary, n.d.). The definition of 'sustainable' as in the context 'sustainable development' can be traced back to 1976, stated as 'Designating forms of human activity (esp. of an economic nature) in which environmental degradation is minimized, esp. by avoiding the long-term depletion of natural resources; of or relating to activity of this type' (Oxford English Dictionary, n.d.). Another major document that helped attach the current context to the term was the World Conservation Strategy published by the International Union for Conservation of Nature (IUCN) in 1980, subtitled 'Living Resource Conservation for Sustainable Development'. (IUCN, UNEP, WWF, FAO, \& UNESCO, 1980) This was further cemented in 1987 by the Brundtland Commission's report.

Similarly, the term 'sustainability' gained its meaning in the current context much more recently. The term had its origins in legal proceedings, earliest recorded use being in 1835; 'the quality of being sustainable by argument; the capacity to be upheld or defended as valid, correct, or true' (Oxford English Dictionary, n.d.). The earliest attempt at defining the term in the context of this writing can be traced back to 1980, with the definition being stated as 'the property of being environmentally sustainable; the degree to which a process or enterprise is able to be maintained or continued while avoiding the long-term depletion of natural resources' (Oxford English Dictionary, n.d.). Going back to Warde's hypothesis - 'the modern notion of sustainability largely draws on ideas developed in the late eighteenth and early nineteenth centuries when new understandings of soil science and agricultural practice combined to develop the idea of a circulation of essential nutrients within ecologies, and hence allow the perception that disruption to circulatory processes could lead to permanent degradation' (Warde, 2011). While the Brundtland Report does not attempt to explicitly define the term 'sustainability', another research published by The World Bank in 1994 defines it as 'sustainability is defined as a requirement of our generation to manage the resource base such 
that the average quality of life that we ensure ourselves can potentially be shared by all future generations' (Asheim \& World Bank, 1994).

The relatively recent origin of the contextual definition for these two terms can further be exhibited when we look at similar words in other languages. Being a native speaker of other languages, Hindi and Bengali, attempts were made into finding equivalent terms for 'sustainable' and 'sustainability' in these two languages. In Hindi, the words related to 'sustainable' are chirsthayi, dheerghkaalik, wahniya and tikau, corresponding to 'stable', 'long-lasting', 'bearing ability' and 'resilient'. For 'sustainability', we get nirantarta, wahniyta, satatata and sandharniyta, corresponding to 'continuation', 'bearing ability', 'persistence' and 'maintaining'. Similarly, in Bengali, the words related to 'sustainable' are tekshoi, shohniyo, annabachinno and shoktishali, which correspond to 'resilient', 'bearing ability', 'continuous' and 'powerful'. For 'sustainability', we have 'shohon shokti', which means 'ability to bear'. As evident above, while there are corresponding phrases for most of the classical definitions of both terms, there is barely any direct translation that relates to the context of the Brundtland Commission's definition. Both 'sustainability' and 'sustainable development' are unique terms in this respect. They only exist in their complete definitions in the English language, having existed there for a mere half of a century. It is truly a creation of the modern world, the solution to problems that also find their origins in the modern world.

\section{The Three Pillar}

A perusal of the Brundtland Commission's report - Our Common Future, and the various surrounding late 20th century texts on 'sustainability' and 'sustainable development', show the gradual emergence of three key fronts, which are required to be attained to achieve true sustainability. The three fronts, though heavily intertwined, are considered as discreet objectives. The quick study of the UN's sustainable development goals (SDGs) shows that the three fronts are integral to the SDG formulation. The fronts are namely - ecological sustainability, social sustainability, and economic sustainability. Ecological sustainability is focused on the protection and care of the environment, ensuring fair use of natural resources. Social sustainability focuses on the functioning of the society, safeguarding culture and organising politics. Economic sustainability focuses on efficiency and checks on the use of human resources. One observation that can be made when studying the origin of the three fronts is that economic sustainability is a relatively recent addition. 
During the late 1960s and early 1970s, eco-activism gained momentum (Demos, 2016). There was an increasing awareness that ecology needed to be cared for. As Jedediah Purdy explains- after nearly ten thousand years of relatively stable climate and burgeoning human wealth, ecological systems are intensely stressed, and that their health or collapse, as well as the shape in which they will survive (if they do), is substantially down to human choices (Purdy, 2015). In the wake of the Industrial Revolution, the world started questioning the single-minded pursuit of economic development. World War II had left a lasting, unfavourable impression on most of the world, and a socio-political crisis was also constant. All of this culminated in the 1972 United Nation's Conference on the Human-Environment, which marked the first time a world body acknowledged ecological and social problems on a global scale. As noted in the official report of the conference - The protection and improvement of the human environment is a major issue which affects the well-being of peoples and economic development throughout the world; it is the urgent desire of the peoples of the whole world and the duty of all Governments (United Nations General Assembly, 1972). This declaration had two aspects. The first is the recognition of an ecological imbalance due to human activities. And second is that this marked the beginning of the UN's rally into promoting economic development as the solution to socio-ecological well-being, rather than being the cause of the problem. Thus, the concept of sustainability expanded to include the three fronts (Purvis, Mao, \& Robinson, 2019).

Often called the three pillars of sustainability, these three fronts have often been depicted in the form of a Venn diagram - three equal circles intersecting, with the centre of the intersection being labelled 'sustainability; while there exist other depictions such as using concentric circles and literal pillars upholding sustainability, the most used depiction is the one using Venn diagram. This form of depicting these three aspects was first presented in the study titled The Concept of Sustainable Economic Development, by economist Edward Barbier, although the exact purpose of the depictions was aimed at dissecting sustainable economic development (Barbier, 1987). By the early 2000s the three-circle diagram, as it was colloquially named, was considered a common view (Giddings, Hopwood, \& O'Brien, 2002).

A literature review brings to light that the first documented attempt to define the three fronts in the present context was made in the publication Global Sustainability: Toward Definition, published in 1987. It noted that the general context in which the term 'sustainability' was used. The social definition focussed on 'the continued satisfaction of basic human needs - food, water, shelter - as well as higher-level social and cultural necessities such as security, freedom, education, employment, and recreation' (Brown, Hanson, Liverman, \& 
Merideth Jr., 1987). The ecological definition focussed on 'natural biological processes and the continued productivity and functioning of ecosystems' and 'protection of genetic resources and the conservation of biological diversity' (Brown, Hanson, Liverman, \& Merideth Jr., 1987). And the economic definition focussed on 'the limitations that a sustainable society must place on economic growth and must deal with nonmarketable and often unquantifiable values of ecosystems and long-term global health' (Brown, Hanson, Liverman, \& Merideth Jr., 1987). It would be misleading to credit this publication for coining the three fronts though. An earlier publication by IUCN, 'World Conservation Strategy', subtitled 'Living Resource Conservation for Sustainable Development', states that 'for development to be sustainable it must take account of social and ecological factors, as well as economic ones' (IUCN, UNEP, WWF, FAO, \& UNESCO, 1980).

When looking at the UN publications and their attempts at defining the three fronts, both 1987's Brundtland Commission's Report and 1992's Agenda 21 (United Nations Conference on Environment and Development, 1992) aim to attach ecological, social, and economic aspects to the development plans. But there is a distinct lack of definition for the three aspects. Post Rio Summit (1992), over the course of three summits, the three fronts took further root in the documentation. In Earth Summit + 5 in 1997, a report on the progress since the Rio Summit states, "Sustainable development may be regarded as the progressive and balanced achievement of sustained economic development, improved social equity and environmental sustainability." (United Nations, 1997) The report of World Summit on Sustainable Development, 2002, mentions that effort is to be made 'promote the integration of the three components of sustainable development - economic development, social development and environmental protection - as interdependent and mutually reinforcing pillars.' (United Nations, 2002) By the Rio+20 summit in 2012, the commitment was explicitly aimed at 'sustainable development and ... ensuring the promotion of an economically, socially and environmentally sustainable future for our planet and for present and future generations.' (United Nations, 2012).

\section{Sustainability in Architecture and Design}

The late 1990s and early 2000s saw a plethora of research centred around the UN documents and their definitions of 'sustainable development'. A good measure to see the progress of this research is to look at the evolution of design and architecture that was practised during this time. Design has always been a display of our reaction to our stimuli. What we design is what we have experienced, what we are experiencing, and what want to experience. The need to find 
refuge from the climate was the starting point of making buildings. The feeling of thermal discomfort led to the design of windows for ventilation. The desire to express creativity led to the evolution of building aesthetics. Thus, it is an iterative process, because we ourselves go through many iterations of our understanding of the stimulus before being able to decipher it. The acknowledgement that the ecological crisis was indeed real, spurred a huge change in the way design was approached. The consequent formation of the concept of 'sustainability' shaped design as well. But owing to the abstract nature of sustainability, there was no single method that governed these new ways of designing.

While everyone agreed that there was a need for an intervention, there was no clarity about what could be done. Latour sums it up briefly, saying that "we have to do something but we are not told what to do" (Latour, 2017). Thus, there exist multiple interpretations and approaches which attempt to deal with this puzzle. As a result, design is a good measure to check our understanding and prepared-ness of the current 'ecological crisis'. At first glance, it seems as though we are progressing in the right direction. While we as a species collectively move through the technological age, our designs seem to digress into going back to nature. There seems to be a consensus that one way to achieve sustainability is to turn back to nature. But therein lies a problem; the lines between what is natural and what is artificial are getting increasingly blurred. As Purdy has elaborated - "The contrast between what is nature and what is not no longer makes sense. The natural and the artificial have merged at every scale. Climate change makes the global atmosphere, its chemistry and weather systems, into Frankenstein's monster- part natural, part made" (Purdy, 2015).

If we want to see this through a certain lens - architecture has moved from trying to adapt to nature to trying to substitute it. In its earliest iterations, architecture was reactionary, to protect oneself from unpleasant environmental stimuli. While at its core, architecture today is still reactionary, architects have also tried to imitate, and subsequently, dominate nature through design. As explained by Esther Choi, “Architecture has long cultivated a tamed version of nature as a decorative extension of itself. Popularized by the discipline's fascination with the modernist rhetoric of providing technologically mediated access to fresh air, sunlight and rooftop gardens; nature has often been slotted by architects into the domains of metaphor, ornament, or atmospheric "special effects"." (Choi, 2019). Choi is critical of 'green architecture', explaining that it has been relegated to being simple imitations - buildings wanting to be nature itself. While her apprehensions are not misplaced, the problem runs deeper, beyond simple imitations and vertical plantations. There is a need to understand that 
'green' does not equate to 'sustainable', or vice versa. Our fundamental inability to differentiate between these two as designers has led to this current situation. It is a two-pronged problem Our insensitivity to the 'ecological crisis', coupled with the confusion created by the political and corporate lobbies, searching for their own definitions to suit their agendas.

This corporate influence on architecture has transformed it from being a function of contextual solutions to becoming commodities, "that alone are supposed to activate ailing economies, attract tourists and investors, and redefine the identity of entire societies" (Arantes, 2018). Arantes further goes on to explain that "this new architectural commodity, which differs fundamentally from precepts of a previous modern period of production, is... from the point of view of ... its economic bases, which combine rent and value in a singular way (Arantes, 2018). This pressure from the demand for economic and social sustainability, coupled with the looming threat of total ecological failure, has placed architecture in a unique position; as the witness to attempts that have been made at satisfying all three sustainability fronts, as discussed previously. Simultaneously, this pressure has also led to the aforementioned 'green architecture'. But the concept of sustainability itself is undergoing scrutiny, with new research by the likes of Bruno Latour, Esther Choi, Jedediah Purdy and Paul Warde are paving the way for changing the way we approach it. A similar shift can also be witnessed in architecture.

As the definitions of sustainability are changing, another observation that can be made is that sustainable development may not always be achievable through infrastructural development. An example of such a scenario would be the Arctic, changing in unpredictable ways due to climate change. The Arctic is a treasure trove of resources. Climate change is increasingly granting us access to these resources. As a result, the entirety of the Arctic is witnessing development in infrastructure. This development, despite being conceived to be sustainable, is often in direct conflict with the interests of the indigenous residents, resulting in a dichotomy of interests. The affected population majorly consists of nomadic reindeer herders, who are finding it increasingly difficult to complete their annual migrations. They are losing their pasture lands, as well as their migratory routes. They understand the importance of the infrastructure, which is being developed, but they must complete their migrations else they would lose their flock. Thus, there is a growing opinion to become sedentary. They cannot do so due to the reindeer being dependent on them, and in turn, them being dependent on the reindeer. In such scenarios, urbanisation without forethought may turn out to be detrimental to the growth of the habitat since it would ensure human survival without considering the primary dwellers - the reindeer. "Most of the definitions we have described either state or imply that 
the goal of sustainability is human survival and do not accept the desirability of a sustainable biosphere without the existence of Homo sapiens" (Brown, Hanson, Liverman, \& Merideth Jr., 1987).

\section{Conclusion}

Despite all misgivings, architects and designers have constantly tried to reinterpret the concept of sustainability and how to achieve it. A surprising array of innovations can be seen when one looks at these attempts. While some designs have been successful in satisfying one of the fronts, others have made efforts to satisfy all three. Many projects have embraced commodification mentioned previously, while others and tried to escape it. The idea that there are 'right' and 'wrong' approaches will always be up for debate, but each interpretation is an attempt by an architect to grasp the true essence of sustainable development.

\section{Bibliography}

Arantes, P. F. (2018). The Rent of Form. (A. Kauffmann, Trans.) Minneapolis: University Of Minnesota.

Asheim, G. B., \& World Bank. (1994). Sustainability : Ethical Foundations and Economic Properties. Washington D.C.: World Bank.

Barbier, E. B. (1987). The Concept of Sustainable Economic Development. Environmental Conservation vol. 14, no. 2, 101-110.

Brown, J. B., Hanson, E. M., Liverman, M. D., \& Merideth Jr., W. R. (1987). Global sustainability: Toward definition. Environmental Management volume 11, no. 5, 713719.

Choi, E. (2019). Sustainability's Image Problem. New York City: Library Stack.

Demos, T. (2016). Decolonizing Nature : Contemporary Art and the Politics of Ecology. Berlin: Sternberg Press.

Giddings, B., Hopwood, B., \& O'Brien, G. (2002). Environment, economy and society: fitting them together into sustainable development. Sustainable DevelopmentVolume 10, Issue 4, 187-196.

IUCN, UNEP, WWF, FAO, \& UNESCO. (1980). World Conservation Strategy: Living Resource Conservation for Sustainable Development. Gland, Switzerland: IUCN. 
Latour, B. (2017). Facing Gaia : Eight Lectures on the New Climate Regime,. (C. Porter, Trans.) Cambridge: Polity.

Oxford English Dictionary. (n.d.). sustain, v. Retrieved from OED:

www.oed.com/view/Entry/195209

Oxford English Dictionary. (n.d.). sustainability, $n$. Retrieved from OED:

www.oed.com/view/Entry/299890

Oxford English Dictionary. (n.d.). sustainable, adj. Retrieved from OED:

www.oed.com/view/Entry/195210

Purdy, J. (2015). After Nature : A Politics for the Anthropocene. Cambridge, Massachusetts: Harvard University Press.

Purvis, B., Mao, Y., \& Robinson, D. (2019). Three pillars of sustainability: in search of conceptual origins. Sustainability Science volume 14, 681-695.

United Nation's Education, Scientific and Cultural Organisation. (n.d.). Sustainable

Development. Retrieved from https://en.unesco.org/themes/education-

sustainabledevelopment/

United Nations. (1997). Overall Progress Achieved Since The United Nations Conference On Environment And Development. United Nations.

United Nations. (2002). Draft plan of implementation of the World Summit. Johannesburg: United Nations.

United Nations. (2012). The Future We Want. Rio de Janeiro: United Nations.

United Nations Conference on Environment and Development. (1992). Agenda 21, Rio

Declaration, Forest Principles. New York: United Nations.

United Nations General Assembly. (1972). Report Of The United Nations Conference On The Human Environment. UN General Assembly.

Warde, P. (2011). “The Invention of Sustainability,” Modern Intellectual History, vol. 8, no.

1. Cambridge:: Cambridge University Press.

World Commission on Environment and Development. (1987). Our Common Future. Oxford: Oxford University Press. 